\title{
The Analysis of Diving Resistance by Using Dry Static Method for Freediving Beginners
}

\author{
Syamsul Bakri \\ Master Program in Sport Sciences \\ Universitas Negeri Yogyakarta \\ Yogyakarta, Indonesia \\ itakoreso7@gmail.com
}

\author{
Suharjana \\ Faculty of Sport Sciences \\ Universitas Negeri Yogyakarta \\ Yogyakarta, Indonesia \\ suharjana_fikuny@yahoo.com
}

\begin{abstract}
Diving skills are techniques carried out by freediving athletes to survive in the water for a longer estimated time more than a regular swimmer. Static dry is a method employed by swimmers to last longer in the water. This research was conducted to analyze resistance duration of freediving beginner athletes diving through the use of dry static method. This research used quantitative research method which was tested on 20 subjects. The data collection techniques employed were tests and measurements which were carried out by using a stopwatch. Then, the data were analyzed by quantitative descriptive analysis. The results showed that the resistance of freediving beginners was categorized in the low category with duration of only 51: 10" up to 55: $45^{\prime \prime}$. Then it was found that the mistake of freediving athletes in diving was due to environmental conditions, fitness, body composition, nutritional status, psychophysical relaxation or reflex diving.
\end{abstract}

Keywords - dry static, dive resistance, freediving, beginner athletes.

\section{INTRODUCTION}

Diving has emerged as an increasingly popular competitive sport in the past 30 years [1]. Freediving is a sport where individuals dive freely by holding their breath in water [2]. Millions of people around the world enjoy snorkeling. Many of them take one deep breath then dive for a few moments. Humans also show a similar behavior, but generally not popular, compared to the water mammals. The individual difference of the decrease in heartbeat rate were observed in the human range from insignificant to $70-80 \%$ change from pre-diving heartbeat rate [3]. In addition, there is need for consideration of some important things when we dive and those things are related life. Respiration is directly related to oxygen in the body. When diving, available oxygen is channeled to the most sensitive organs of the body including asphyxia, heart and brain as well as the functioning of the muscle [3].

Good respiration is important when practicing freediving so as to easily balance the oxygen needed with $\mathrm{CO}_{2}$ that enters the body. But in reality, many athletes are not too concerned with good breathing techniques when they start diving. Unnoticed, this will have effect on their respiratory system in the future considering the fact that health must be considered by a freediving athlete. One of the best ways by which freediving athletes can be helped to maintain good respiratory system is by providing breathing training methods for them.
By considering the human respiratory system, while diving, heartbeat rate decreases more when lung volume is held at $60 \%$ compared to $85 \%$ of vital capacity. This happens because as a result of smaller lung volume, activity in the lungs adapts slowly to minimal or no stretch receptor. Furthermore, it is speculated that in a larger lung volume, intrathoracic pressure hampers the venous return and reduces stroke volume which will partly be compensated by an increase of heartbeat rate [4]

Freediving is one of the extreme sports carried out in water. Every freediving athlete has the opportunity to experience blackout (inability to survive in the water) which can cause death. Nonetheless, freediving can be used to bring about the improvement of the mental capacity as well as increase the capacity of the lung. The main characteristic that distinguishes freediving to other sports is that, in frediving, the performance of underwater athletes is related to their own physiological and psychological limits. In addition, the athletes do not have direct contact with their rivals. In other words, freediving athletes depend on themselves when diving [2].

Special Region of Yogyakarta, for example, has some freediving communities, such as Jogja Freediving Unit (JFU) and Ambifi. The two communities' activities have been used as a place for beginner athletes who desire to learn and improve diving achievements in DIY. Based on the initial observations that the researchers conducted on both freediving communities including Jogja Freediving Unit and Ambifi, the researchers found that when the athletes dive, their respiratory resistance is not optimal. This can be seen from the inability of athletes to survive in water for a long time. In order to support the finding, the researchers conducted interviews with two freediving trainers to ask what obstacles occurred during their training. Each of the trainers said that the obstacles that often occur in beginner athletes are their respiratory capacity and short duration while diving which causes the athletes' resistance in diving not to be optimal. Based on the existing gaps, the researchers were interested in analyzing dry static techniques on diving athletes' diving resistance.

This research was aimed at analyzing the diving resistance through the use of dry static method for beginner athletes of freediving. The purpose of this study was evaluated through field testing, the duration of diving resistance time, and other factors that influence the dive resistance of freediving beginners. 


\section{METHOD}

\section{A. Type of the research}

This research made use of quantitative descriptive method which has been defined to be a research based on data from systematic empirical reality that can be measured by numbers which are then described in narrative form.

\section{B. Time and place of the research}

This research was conducted for four weeks, precisely in July 2018. The research location was the FIK UNY swimming pool. Ideally, four weeks is enough to measure the diving resistance of a freediving beginner athletes, considering that the activities do not require long time for the collection of data. The research was conducted every Sunday at 4:00 p.m.

\section{Subject of the Research}

The population used in this research was Yogyakarta beginner athletes of freediving. The entire population in this research had some similar criteria; training in the same pool, having an age susceptibility that is relatively the same (between 20-40 years old), having practiced together regularly for more than a year, and willing to be a research subject. The subjects used in this research were 20 people from Yogyakarta beginner athletes of freediving.

\section{Procedure of the research}

This research employed the use of quantitative descriptive design where researchers observed the behavior of freediving beginners. The researchers directed the subjects to hold their breath on land, a process that is also known as dry static.

\section{E. Technique for the collection of data}

The techniques used in collecting the data that was used in this research were tests and measurements to obtain objective data about the diving resistance of freediving beginners. Tests and measurements in this study were conducted four times and the test results were recorded in the form of time or duration.

\section{F. Instrument of the research}

This research was measured based on diving resistance indicators and using stopwatch to find out how long the each of the subjects was able to dive.

\section{RESULTS AND DISCUSSION}

Apart from the methodology and procedures performed on freediving beginners to measure diving resistance, various results and discussion of dry static related theories were also applied to the subjects. The results and discussions in this study are presented as follows.

\section{A. Results}

In the previous section, researchers have conducted tests and measurements on the application of static dry techniques to measure dive resistance in freediving beginners. Data were obtained using diving resistance indicators and analyzed using quantitative descriptive techniques. The data on diving resistance value for freediving beginners are presented in the table below.
TABLE I. The DATA of Diving Resistance

\begin{tabular}{|l|l|c|c|}
\hline Club & $\begin{array}{c}\text { Diving } \\
\text { Duration } \\
\text { Average }(\overline{\boldsymbol{x}})\end{array}$ & $\begin{array}{c}\text { Average } \\
\text { Difference }\end{array}$ & $\begin{array}{c}\text { Percentage } \\
(\%)\end{array}$ \\
\hline JFU & $55: 45^{\prime \prime}$ & \multirow{2}{*}{$4: 35 \%$} & $7,25 \%$ \\
\hline Amfibi & $51: 10 \%$ & & \\
\hline
\end{tabular}

Based on the test which was conducted on 20 people who were classified into two freediving beginner athletes clubs, the researchers found that the average diving durations are 55:45" and 51:10". Moreover, the average difference between the clubs is only $4: 35^{\prime}$. This result is far from the standard for a freediving athlete who has dived for over a year. This can be seen by using the following normal curves:

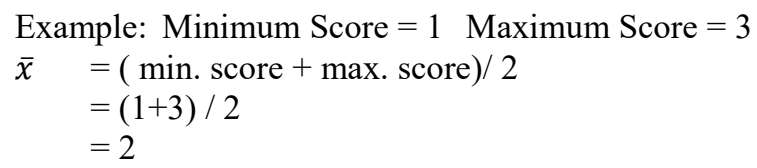

Category:

Not meet (Low) $\quad=0-1$,

Partially meet (Fair) $\quad=1$ ' -2 '

Fully meet (High) = $\quad 2$ ' -3 ,

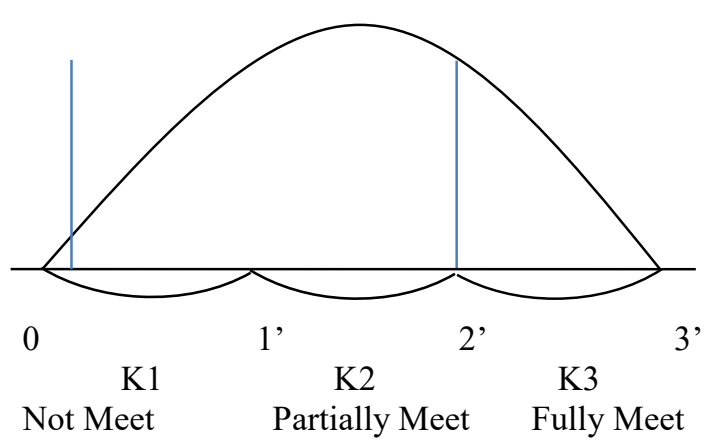

Fig 1. Normality Curve

\section{B. Discussion}

The biggest reason why dry static was applied as a strategy in the measurement of diving resistance is because the results gotten from the use of dry static technique is believed to have the ability of influencing the limit of diving resistance of a freediving beginner athlete. Based on this research, it was found that all the diving resistance test results and measurements were in the low category (not meet). This can be seen from the average duration of diving of only 51: 10 " to 55: 45 ". This duration is very low for a freediving beginner who is always in contact with water. A beginner athlete should be able to show progress in terms of controlling himself/herself while in the water considering the fact that the subject has been freediving for more than a year. Various factors influence the ability of a beginner athlete to hold his/her breath while diving and they may be either internal or external factors.

The research found that environmental conditions, fitness, body composition, nutritional status, psychophysical relaxation or reflex diving are some of the factors that can affect an individual's metabolic rate during diving [6]. When a person is relax, there will be stability of thoughts and actions to perform such a complex action (diving). Besides, lack of sleep also affects a freediving athlete in diving as the body is not ready to 
do activities that are quite complex and it may cause inability to dive longer in the water.

Dry static method is not the only way that can be used in measuring the diving resistance of a freediving athlete, there are some other methods and techniques that are also quite interesting to be applied. One of them is by using the static apnea method. Static apnea is also closely related to everything that must be considered in freediving.

\section{CONCLUSION}

The result of the research were analyzed and related to the theory, and it can be concluded that the diving resistance of the freediving beginners is still in the low category. This is shown from the average yield of diving resistance for freediving beginners to be only 51: 10 " up to 55: 45 ". These numbers are still in a low standard for a beginner athlete who actually have to stay in the water for 2-3 minutes. This low resistance of diving athletes are related to their lack of relaxation before diving. In addition, lack of sleep also affects a freediving athlete in diving, which causes the inability of athletes to control themselves to dive longer in the water.

Based on this research, it is recommended that the readers and subsequent researchers develop concepts and ideas about freediving so that the community will know more about freediving, and even benefit from it. A concept that might be done is to try to apply the static apnea method for freediving athletes. It would be a new discovery if researchers can develop this idea in the form of scientific research and writing.

\section{ACKNOWLEDGMENT}

Special thanks to my beloved campus, State University of Yogyakara and the Postgraduate Program which have been helpful in the completion of this thesis. Moreover, many thanks to the thesis supervisor, Mr. Suharjana, who has guided me to finish this research. And the last, I present this thesis to my parents who are my greatest inspiration in everything.

\section{REFERENCE}

[1] Bain, A. R., Drvis, I., Dujic, Z., MacLeod, D. B.,z \& Ainslie, P. N. Physiology of static breath holding in elite apneists. Experimental physiology, 103(5), 635-651. 2018.

[2] Alkan, N., \& Akış, T. Psychological characteristics of free diving athletes: A comparative study. International Journal of Humanities and Social Science, 3(15), 150-157. 2013.

[3] Schagatay, E., van Kampen, M., Emanuelsson, S., \& Holm, B. Effects of physical and apnea training on apneic time and the diving response in humans. European journal of applied physiology, 82(3), 161-169. 2000.

[4] Foster, G. E., \& Sheel, A. W. The human diving response, its function, and its control. Scandinavian journal of medicine \& science in sports, 15(1), 3-12. 2005

[5] Sugiyono, Metode penelitian kuantitatif kualitatif dan R \& D, Bandung: Alfabeta, 2015.

[6] Fernández, F., González-Ravé, J.M., \& Juárez, D. Breath-hold diving performance

Journal of Human Sport and Exercise, 12(3), 582-592. 2017. 